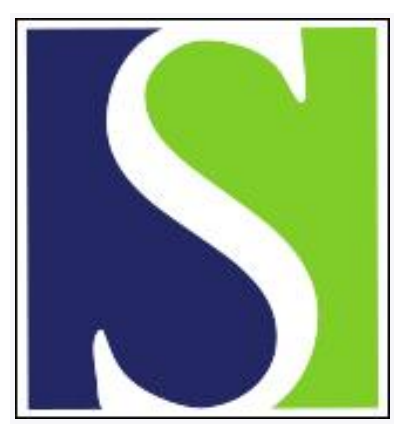

Scand J Work Environ Health 2007;33(4):280-285

https://doi.org/10.5271/sjweh.1144

Issue date: 31 Aug 2007

Eye and airway symptoms in low occupational exposure to toluene diisocyanate

by Littorin M, Axmon A, Broberg K, Sennbro C], Tinnerberg H

Affiliation: Department of Occupational and Environmental Medicine, University Hospital, Lund, Sweden. margareta.littorin@med.lu.se

Refers to the following text of the Journal: 2004;30(5):371-378

Key terms: air level; airway symptom; biomarker; dose-response relationship; eye symptom; health effect; isocyanate; occupational exposure; toluene diisocyanate

This article in PubMed: www.ncbi.nlm.nih.gov/pubmed/17717620 


\title{
Eye and airway symptoms in low occupational exposure to toluene diisocyanate
}

\author{
by Margareta Littorin, MD, ${ }^{1}$ Anna Axmon, PhD, ${ }^{1}$ Karin Broberg, PhD, ${ }^{1}$ Carl-Johan Sennbro, PhD, ${ }^{1}$ Håkan \\ Tinnerberg, $P h D^{1}$
}

\begin{abstract}
Littorin M, Axmon A, Broberg K, Sennbro CJ, Tinnerberg H. Eye and airway symptoms in low occupational exposure to toluene diisocyanate. Scand J Work Environ Health 2007:33(4):280-285.
\end{abstract}

\begin{abstract}
Objectives Exposure to diisocyanates is a well known occupational hazard. The objective of this study was to determine the possibility of an association between low exposure to toluene diisocyanate (TDI) (airborne isocyanates and biomarkers of isocyanates in plasma and urine) and symptoms of the eyes and upper and lower airways.

Methods Altogether 136 workers occupationally exposed to TDI and 118 unexposed employees were studied. A physician compiled thorough medical and occupational histories and registered symptoms, total and workrelated, of the eyes, nose, and lower airways. The exposure was assessed with personal air measurements and with biomarkers of exposure in plasma and urine. The average exposure in the ambient air at the workplace of the exposed participants was below $1 \mathrm{ppb}$.

Results Compared with the unexposed group, the exposed workers reported more total symptoms of the eyes and lower airways, as well as nose bleeding. A similar pattern, with even higher odds ratios, was observed for work-related symptoms. However, only eye symptoms proved to be significantly associated with the exposure, notably with all of the exposure measures. The risk was more pronounced for exposure to 2,4-TDI than for exposure to 2,6-TDI.

Conclusions Even very low exposure to TDI is related to negative health effects on exposed workers. Clear dose-response relationships were observed between three different measures of exposure and symptoms of the eyes.
\end{abstract}

Key terms air level; biomarker; dose-response; health effect; isocyanate.

Exposure to diisocyanates is a well known cause of respiratory symptoms. Apart from asthma, symptoms such as cough, wheezing, and dyspnea are commonly reported (1-4). Other effects are hypersensitivity pneumonitis and an accelerated decline of lung function (2, 5-7). Moreover, exposure to diisocyanates also often causes symptoms of the upper airways and eyes (1-2, $8-9)$. However, the extent of these symptoms in today's fairly low exposure conditions is not well known.

Exposure to isocyanates is commonly monitored by measuring the concentration in air, and it is regulated through the use of exposure limits for airborne isocyanates. The typical occupational exposure limit for 8 hours in most western countries is $5 \mathrm{ppb}$-with a shortterm exposure limit for 5 minutes at $10 \mathrm{ppb}$. In Sweden, the occupational exposure limits were lowered to 2 and
5 ppb, respectively, in October 2005 (10). However, such exposure can also be monitored by measuring biomarkers in urine or plasma (11), the urinary biomarker reflecting exposure the actual day or days of exposure and the plasma biomarker representing exposure during the last month. In most previous studies in which exposure-response relations have been investigated, exposure to isocyanates has been presented as airborne concentrations only.

The objective of our present study was to characterize possible associations between different exposure measures (isocyanates in air, biomarkers of isocyanates in plasma and urine) for toluene diisocyanate (TDI) and symptoms of the eyes and the upper and lower airways using a cross-sectional approach. Thus a group of workers exposed mainly to TDI and an occupationally

Reprint requests to: Dr M Littorin, Department of Occupational and Environmental Medicine, University Hospital, Lund, Sweden. [E-mail: margareta.littorin@med.lu.se] 
unexposed group were examined for isocyanate exposure and health effects.

\section{Study population and methods}

\section{Plants and exposure to isocyanates}

Eleven plants in the southern part of Sweden, described earlier in detail by Sennbro et al (12), were included in the study. There were five molding plants, two continuous-foaming plants, two flame-lamination plants, and two plants with low heating or nonheating processes. At all of the plants, TDI or TDI-based polyurethane was used in the manufacturing process. In four of the five molding plants, methylene diphenyl diisocyanate (MDI) was used in the manufacturing process although the exposures in air were low or nondetectable. At one of these four plants, isophorone diisocyanate was used as well. In the continuous-foaming plants, the main exposure arose at work in the ventilated tunnel, but during this work the workers always used personal respirators. At the flamelamination plants, the workers were exposed to thermal degradation products of ready-made polyurethane, and, therefore, the exposure was a mix of mono- and diisocyanates, aminoisocyanates, and amines. The exposure to TDI in the different plants (outside the respirators) comprised, on the average and in decreasing order, "continuous foaming", "flame lamination", "molding", "low heating or nonheating processes". The median personal 8-hour exposures to TDI at the different plants were $0.63-4.0 \mathrm{ppb}$ for the continuous foaming , 0.76-1.5 $\mathrm{ppb}$ for flame lamination, $0.17-0.64 \mathrm{ppb}$ for molding, and $0.02-0.05 \mathrm{ppb}$ for the low heating or nonheating processes. However, there was a variation of exposure levels by a factor of 4 between similar plants and by a factor of 3 between different shifts performing the same tasks at one plant. There was also a large variation in exposure between workers performing the same work in the same shift and plant.

\section{Study population}

This was a cross-sectional study of 136 exposed and 118 unexposed employees. The exposed group comprised TDI-exposed workers from the plants included in the investigation (87 from molding plants, 11 from continuous-foaming plants, 13 from flame-lamination plants, and 25 from low heating or nonheating processes). Only those working with TDI, or working in the same hall as people working with TDI, and present at work on the days of the examinations were included in the study. The occupationally unexposed employees were recruited from five different activities in southern Sweden, where no isocyanates, polyurethanes, or other plastics were handled and no heating operations were performed. They consisted of assemblers of armature at an electric light fittings company, operators at a dairy plant, meat cutters at a butchery, postmen, and employees at a supermarket (13). Some characteristics of the participants are presented in table 1 . The median age of the exposed and unexposed groups was 36 (range 19-63) and 41 (range 20-63) years, respectively. The study was approved by the Regional Ethical Committee at the Lund University in Lund, Sweden. Written informed consent was obtained from all of the participants.

\section{Health examinations}

A physician compiled thorough medical and occupational histories from structured interviews. A history of atopy and ever having had physician-diagnosed asthma or bronchitis was recorded. Additional questions included "Do you usually cough?" (denoted "cough" in the following) and "Do you usually have a cough with phlegm?" (denoted "cough with phlegm"). The participants were also asked whether they usually wheezed when having a cold or on other occasions ("wheeze"). Furthermore, the presence of attacks of symptoms during the past 12 months was requested and included symptoms of the eyes (at least one of itching, running, or burning), nose (running, stuffiness, and sneezing, as well as nose bleeding), and lower airways (severe dry

Table 1. Characteristics of the136 workers exposed to toluene diisocyanate and the 118 unexposed employees and the symptoms of the eyes and airways.

\begin{tabular}{|c|c|c|c|c|}
\hline \multirow[t]{2}{*}{ Characteristic } & \multicolumn{2}{|c|}{ Exposed $^{\mathrm{a}}(\mathrm{N}=136)$} & \multicolumn{2}{|c|}{ Unexposed a $(\mathrm{N}=118)$} \\
\hline & $\mathrm{N}$ & $\%$ & $\mathrm{~N}$ & $\%$ \\
\hline Male & 110 & 81 & 57 & 48 \\
\hline Atopic $^{b}$ & 38 & 28 & 33 & 28 \\
\hline Smoker and ex-smoker & 89 & 65 & 83 & 70 \\
\hline \multicolumn{5}{|l|}{ History (ever) } \\
\hline Asthma & 12 & 9 & 13 & 11 \\
\hline Bronchitis & 13 & 10 & 22 & 19 \\
\hline \multicolumn{5}{|l|}{ Symptoms usually } \\
\hline Cough & 38 & 28 & 19 & 16 \\
\hline Cough with phlegm & 45 & 34 & 28 & 24 \\
\hline Wheeze & 35 & 27 & 26 & 22 \\
\hline \multicolumn{5}{|c|}{ Attacks of symptoms (total/work-related) } \\
\hline Eye symptoms & $59 / 49$ & $44 / 37$ & $26 / 5$ & $22 / 4$ \\
\hline Running nose & $46 / 30$ & $35 / 23$ & $32 / 9$ & $27 / 8$ \\
\hline Stuffed nose & $52 / 29$ & $39 / 22$ & $35 / 6$ & $30 / 5$ \\
\hline Sneezing & $56 / 40$ & $42 / 30$ & $52 / 12$ & $44 / 10$ \\
\hline Nose bleeding & $29 / 15$ & $22 / 12$ & $7 / 1$ & $6 / 1$ \\
\hline Wheezing, etc & $42 / 33$ & $31 / 24$ & $24 / 2$ & $20 / 2$ \\
\hline Dry cough & $39 / 28$ & $29 / 21$ & $13 / 3$ & $11 / 3$ \\
\hline
\end{tabular}

a Information may be missing for up to six exposed persons and for one unexposed person.

${ }^{b}$ Determined by the Phadiatop test, but for five exposed and five unexposed persons determined from their medical history. 
cough and at least one of wheezing, dyspnea, or chest tightness, denoted as "wheezing, etc") (table 1). Workrelated symptoms were defined as those present during workdays or at night after work and disappearing or declining on weekends or holidays.

The employees were physically examined during workdays in the factory. Venous blood and urinary samples were also collected during work and stored at $-20^{\circ} \mathrm{C}$. Serum was screened for atopy with the use of the Phadiatop test, which was considered positive when at least 1 of 10 common airborne allergens produced a response.

\section{Air and biological monitoring methods}

Air monitoring methods. Personal airborne exposure was measured during one shift for 79 of the exposed workers examined (and, in addition, for another 15 exposed workers from other shifts) with single glass-fiber filters impregnated with 2-methoxyphenyl piperazine (14-15). An analysis of the isocyanates was performed by liquid chromatography combined with tandem mass spectrometry as described by Östin et al (16). The personal 8-hour time-weighted average levels ranged from below the limit of quantification to $2.6 \mathrm{ppb}$ for 2,4-TDI and from 0.01 to $3.6 \mathrm{ppb}$ for 2,6 -TDI $(12,15)$. For the remaining 57 workers participating in the medical examinations, the full-day personal exposures were estimated from a combination of department, task, and results obtained with the air measurements. For the workers at the continuous-foaming plant, the personal air measurements were made outside the used personal protective

Table 2. Total and work-related symptoms among the 136 workers exposed to toluene diisocyanate when compared with 118 unexposed employees. Crude and adjusted (for gender, age, and smoking) effect estimates have been presented as odds ratios (OR) and for the adjusted estimates with $95 \%$ confidence intervals $(95 \% \mathrm{Cl})$.

\begin{tabular}{|c|c|c|c|c|c|c|}
\hline \multirow[t]{3}{*}{ Exposure variable } & \multicolumn{3}{|c|}{ Total symptoms } & \multicolumn{3}{|c|}{ Work-related symptoms } \\
\hline & \multicolumn{3}{|c|}{ Crude OR Adjusted } & \multirow[t]{2}{*}{ Crude OR } & \multicolumn{2}{|c|}{ Adjusted } \\
\hline & & $\mathrm{OR}$ & $95 \% \mathrm{Cl}$ & & $\mathrm{OR}$ & $95 \% \mathrm{Cl}$ \\
\hline \multicolumn{7}{|l|}{ Usually } \\
\hline Cough & 2.0 & 2.7 & $1.3-5.3$ & - & - & \\
\hline Cough with phlegm & 1.6 & 1.9 & $1.0-3.6$ & - & - & \\
\hline Wheeze & 1.1 & 1.3 & $0.70-2.5$ & - & - & \\
\hline \multicolumn{7}{|l|}{ Attacks of } \\
\hline Eye symptoms & 2.8 & 2.7 & $1.5-4.9$ & 13 & 10 & $3.4-30$ \\
\hline Running nose & 1.4 & 1.5 & $0.84-2.7$ & 2.6 & 1.7 & $0.63-4.6$ \\
\hline Stuffed nose & 1.5 & 1.4 & $0.81-2.6$ & 4.9 & 3.7 & $1.3-11$ \\
\hline Sneezing & 0.94 & 1.3 & $0.72-2.2$ & 2.6 & 3.2 & $1.4-7.7$ \\
\hline Nose bleeding & 4.6 & 4.1 & $1.6-10$ & - & - & \\
\hline Wheezing, etc & 1.8 & 1.8 & $0.96-3.4$ & 24 & 21 & $2.6-161$ \\
\hline Dry cough & 3.4 & 3.5 & $1.7-7.3$ & 9.9 & 11 & $2.3-50$ \\
\hline
\end{tabular}

equipment, and they were not included in the analysis of the association between air levels and symptoms.

Biomonitoring methods. Urine samples were collected twice, once as a pooled sample during the last 4 hours of the shift on the day of the air sampling and once on the day of the health examination. Plasma samples were collected on the day of the health examination, which took place within 2 weeks of the day of the air sampling. The collection of the biological samples has been described in detail by Sennbro et al (17). For the workers who had given two urinary samples, the sample collected on the day of the health examination was used in the statistical analyses. All of the biological samples were stored at $-20^{\circ} \mathrm{C}$ until the day of the analysis. The biomarker levels in the urinary and plasma samples were analyzed as TDI-related diamines 2,4- and 2,6toluenediamine (2,4-TDA and 2,6-TDA, respectively) after hydrolysis for 24 hours in $0.3 \mathrm{M}$ sodium hydroxide. The diamines were extracted with toluene, derivatized with pentafluoropropionic acid anhydride, and quantified by gas chromatography and mass spectrometry. Each sample was analyzed at least twice, and the precision was $7-18 \%$ (18).

On the day of the health examinations, the levels of 2,4-TDA and 2,6-TDA in urine ranged from the limit of detection $(0.41 \mathrm{nmol} / \mathrm{l})$ to 623 and $353 \mathrm{nmol} / \mathrm{l}$, respectively, and in plasma from the limit of detection to 254 and $509 \mathrm{nmol} / \mathrm{l}$, respectively (12). When measured on the same day, the individual air measurements correlated fairly well with the biomarkers in urine [2,4-TDA versus 2,4-TDI: Spearman's $r(\mathrm{rS})=0.75$ and 2,6-TDA versus 2,6-TDI: $r S=0.76$ (17)]. There were also correlations between the air levels and the corresponding plasma biomarkers ( 0.50 for 2,4-TDI and 0.78 for 2,6-TDI). In addition, 2,4-TDA [rS=0.90 (18)] in urine and plasma correlated, as did 2,6-TDA ( $\mathrm{rS}=0.85)$ in urine and plasma.

\section{Statistical methods}

The risk associated with exposure (either dichotomous as in table 2 or continuous as in table 3 ) was estimated by odds ratios (OR) with $95 \%$ confidence intervals $(95 \%$ $\mathrm{CI}$ ) calculated using an unconditional logistic regression. Both crude and adjusted estimates have been presented. Adjustments were made for age, gender, and smoking (nonsmoker versus smoker and ex-smoker). Since atopy may be either a confounder or an effect modifier, we tried both. Including atopy in the multivariate models changed the effect estimates only very slightly, and it was not included as a confounder in the final models. Moreover, there were no obvious interactions between atopy and exposure. Spearman's test was used for the tests of correlation. $\mathrm{P}<0.05$ (two-tailed) was considered statistically significant. 
Table 3. Risk of eye symptoms from exposure to toluene diisocyanate (TDI) in air, plasma, and urine for the 136 exposed workers. The risk has been estimated as crude and adjusted (for gender, age, and smoking) odds ratios (OR) and for the adjusted OR with $95 \%$ confidence intervals $(95 \% \mathrm{Cl})$. For airborne isocyanates, the OR represents the increase in risk for each unit of increase in exposure, and, for the biomarkers in plasma and urine, the increase in risk for each 100 units of increase in exposure. [A-TOT $=2,4$ - and 2,6-TDI in air (ppb), A-2,4-TDI = 2,4-TDI in air (ppb), A-2,6-TDI $=2,6$-TDI in air (ppb), P-TOT = biomarkers of 2,4- and 2,6-TDI in plasma $(\mathrm{nmol} / \mathrm{l}), \mathrm{P}-2,4-\mathrm{TDI}=$ biomarkers of $2,4-\mathrm{TDI}$ in plasma $(\mathrm{nmol} / \mathrm{I}), \mathrm{P}-2,6-\mathrm{TDI}=$ biomarkers of 2,6-TDI in plasma $(\mathrm{nmol} / \mathrm{l}), \mathrm{U}-$ TOT = biomarkers of 2,4- and 2,6-TDI in urine (nmol/I), U-2,4-TDI $=$ biomarkers of $2,4-\mathrm{TDI}$ in urine $(\mathrm{nmol} / \mathrm{I}), \mathrm{U}-2,6-\mathrm{TDI}=$ biomarkers of 2,6-TDI in urine (nmol/l)

\begin{tabular}{|c|c|c|c|c|c|c|}
\hline \multirow[t]{3}{*}{ Exposure variable } & \multicolumn{3}{|c|}{ Total eye symptoms } & \multicolumn{3}{|c|}{ Work-related eye symptoms } \\
\hline & \multirow[t]{2}{*}{ Crude OR } & \multicolumn{2}{|c|}{ Adjusted } & \multirow[t]{2}{*}{ Crude OR } & \multicolumn{2}{|c|}{ Adjusted } \\
\hline & & $\mathrm{OR}$ & $95 \% \mathrm{Cl}$ & & $\mathrm{OR}$ & $95 \% \mathrm{Cl}$ \\
\hline A-TOT & 2.1 & 2.0 & $1.1-3.6$ & 3.1 & 2.4 & $1.3-4.4$ \\
\hline A-2,4-TDI & 5.9 & 6.1 & $1.1-33$ & 5.1 & 3.5 & $0.69-18$ \\
\hline A-2,6-TDI & 1.9 & 1.8 & $0.63-5.0$ & 2.4 & 2.1 & $0.74-6.1$ \\
\hline Р-TOT & 1.4 & 1.3 & $1.0-1.8$ & 1.8 & 1.6 & $1.2-2.2$ \\
\hline P-2,4-TDI & 2.4 & 2.2 & $1.2-4.0$ & 4.2 & 3.4 & $1.8-6.6$ \\
\hline P-2,6-TDI & 1.5 & 1.4 & $0.91-2.2$ & 2.3 & 1.9 & $1.2-3.0$ \\
\hline U-TOT & 1.5 & 1.4 & $1.0-1.9$ & 2.0 & 1.7 & $1.2-2.5$ \\
\hline U-2,4-TDI & 2.6 & 2.3 & $1.1-4.8$ & 5.8 & 4.2 & $1.7-10$ \\
\hline U-2,6-TDI & 1.7 & 1.6 & $0.98-2.8$ & 2.6 & 2.1 & $1.2-3.7$ \\
\hline
\end{tabular}

\section{Results}

First, we analyzed whether there were any differences in the risk of disease and symptoms between the exposed and unexposed employees (table 1). The exposed workers presented a history of asthma and bronchitis less often. In the comparison between the cohort of exposed workers (not taking the individual levels of exposure into consideration) and that of the unexposed, a large increase in total eye symptoms was found for the exposed workers (table 2). An increase was also observed for symptoms of the lower airways — cough, cough with phlegm, and attacks of dry cough. Of the nose symptoms investigated, only nose bleeding was associated with the exposure. Strong associations were observed between the exposure and the work-related symptoms, in particular for attacks of eye symptoms, wheezing etc, and dry cough. No effect estimates could be calculated for work-related nose bleeding, since only one person in the unexposed group reported this symptom.

When continuous measures of exposure within the cohort of exposed workers were used, only eye symptoms turned out to be statistically significantly associated with the exposure measures (table 3). Work-related eye symptoms displayed even stronger associations.

When the 2,4-TDI and 2,6-TDI exposure measures were analyzed separately, the risk of developing eye symptoms was more pronounced for exposure to 2,4TDI (table 3). This association was observed for both the air levels and the biomarkers in plasma and urine. The same, and even stronger, pattern of associations was observed for work-related eye symptoms, particularly with regard to the association with the biomarkers. If both the 2,4-TDI and the 2,6-TDI measures in air, urine, or plasma were used together in the models, the effect from 2,4-TDI on the eyes was still more pronounced (not shown in the table). However, the two TDI isomers correlated $(\mathrm{rS}=0.79, \mathrm{P}=0.01)$, as did the corresponding biomarkers 2,4-TDA and 2,6-TDA in urine ( $\mathrm{rS}=0.86$, $\mathrm{P}=0.01)$ and plasma $(\mathrm{rS}=0.87, \mathrm{P}=0.01)$.

No clear patterns emerged for the other exposure-response relationships.

\section{Discussion}

To our knowledge, studies of medical effects in relation to both air levels and biomarkers of isocyanates have not been presented earlier. Our study showed a marked increase in symptoms of the eyes and airways among workers exposed to low levels of TDI as compared with the corresponding symptoms of a group of unexposed workers. Most apparent was the increase in nose bleeding, for which the risk seemed to be four times higher. Dry cough and eye symptoms were increased as well. Even stronger associations were found when work-related symptoms were analyzed (eg, work-related eye symptoms, which had an OR of 10, dry cough, and wheezing, etc) were similarly increased. Furthermore, for symptoms of the eyes, dose-response associations were observed.

The dose-response analyses between the eye symptoms and the different measures of isocyanate exposure were consistent. This finding was not unexpected, since there was a high correlation between personal air levels and biomarker levels (17). To our knowledge, different risk estimates for the two isomers of TDI, 2,4-TDI and 2,6-TDI, have not earlier been assessed. Our results suggest that 2,4-TDI is more harmful to the eyes than 2,6TDI, since an up to three times higher risk was observed for this isomer. This finding agrees with what is known about the reactivities of these isomers, for which the isocyanate group in the 4 position is more reactive than that in the 2 position due to steric hindrance (19).

Others have reported on symptoms such as eye irritation and cough, mostly occurring at higher mean or peak levels of exposure than in our case $(1,8)$. However, asthma-like symptoms have been described also in plants particularly designed and operated to control exposure to isocyanates [ie, MDI $(20,21)]$. Furthermore, respiratory symptoms and new onset asthma have been observed at 
very low levels of exposure to TDI [0.3 to $3 \mathrm{ppb}$ (22)]. On the other hand, in the settings of our study, as is the case of most other industrial settings, there were other concomitant exposures (ie, to dusts).

In western industrialized countries, the incidence of isocyanate-induced asthma has decreased $(6,23,24)$. In recent years, at most, a handful of cases per year have been registered in Sweden. This circumstance probably reflects improvements in the work environment, but may be due partly to the preemployment health examinations required before people enter jobs in which isocyanates are handled. Thus asthmatics should not be eligible for employment, and the workforce in the Swedish polyurethane industry is a selected and, concerning airway disease, rather healthy group. As should be expected, the exposed workers in our study had suffered slightly less from obstructive diseases than the referents. From that viewpoint, the high number of exposed workers with airway symptoms is remarkable. However, dose-response relationships with TDI were not observed. One reason may be that the cross-sectional study design used was not optimal because the workers with workrelated symptoms, at least when severe, would have been moved to less exposed worktasks, become sicklisted, or had had to leave the job. Another circumstance that may have obstructed the possibility of identifying dose-response associations is the complex exposure in the work environments. Other respiratory irritants, like dusts originating from polyurethane and other matter, were present at all of the plants, and, often, in addition, organic solvents were used as releasing agents. Thus the symptoms observed in our study may have been caused by combined exposures. In addition, skin exposure, which was certainly present at these workplaces, may obscure dose-response relationships (25). Such relationships may also be affected by individual susceptibility factors, such as genetically influenced metabolic and immunologic profiles (unpublished data of Broberg et al, submitted). However, we did not observe significant confounding by atopy, nor were there any interactions with atopy.

In this study we have shown that even very low exposure to TDI is associated with negative health effects. A clear dose-response relationship was found between exposure and symptoms of the eyes. The relationship was consistent with different measures of exposure-air measurements and biomarkers in urine and plasma.

\section{Acknowledgments}

Financial support for this work was obtained from the AFA Foundation, Sweden, from the Swedish Council for
Work Life and Social Research, and from the Swedish Research Council.

The authors wish to thank the companies and workers for their participation. We would also like to acknowledge the skillful assistance of the regional nurses Kerstin Diab and Inger Bensryd.

\section{References}

1. Lee HS, Phoon WH. Diurnal variation in peak expiratory flow rate among workers exposed to toluene diisocyanate in the polyurethane foam manufacturing industry. Br J Ind Med. 1992;49:423-7.

2. Baur, X, Marek W, Ammon J, Czuppon AB, Marczynski B, Raulf-Heimsoth M, et al. Respiratory and other hazards of isocyanates. Int Arch Occup Environ Health. 1994;66:141-52.

3. Liu Q, Wisnewski AV. Recent developments in diisocyanate asthma. Ann Allergy Asthma Immunol. 2003;90:35-41.

4. Wang ML, Petsonk EL. Symptom onset in the first 2 years of employment at a wood products plant using diisocyanates: some observations relevant to occupational medical screening. Am J Ind Med. 2004;46:226-33.

5. Diem JE, Jones RN, Hendrick DJ, Glindmeyer HW, Dharmarajan V, Butcher BT, et al. Five-year longitudinal study of workers employed in a new toluene diisocyanate manufacturing plant. Am Rev Respir Dis. 1982;126:420-8.

6. Ott MG, Diller WF, Jolly AT. Respiratory effects of toluene diisocyanate in the work-place: a discussion of exposure-response relationships. Crit Rev Toxicol. 2003;33:1-59.

7. Omae K, Higashi T, Nakadate T, Tsugane S, Nakaza M, Sakurai H. Four-year follow-up of effects of toluene diisocyanate exposure on the respiratory system in polyurethane foam manufacturing workers, II: four-year changes in the effects on the respiratory system. Int Arch Occup Environ Health 1992;63:565-9.

8. Omae K, Nakadate T, Higashi T, Nakaza M, Aizawa Y, Sakurai $\mathrm{H}$. Four-year follow-up of effects of toluene diisocyanate exposure on the respiratory system in polyurethane foam manufacturing workers, I: study design and results of the first cross-sectional observation. Int Arch Occup Environ Health. 1992;63:559-64.

9. Littorin M, Welinder H, Skarping G, Dalene M, Skerfving S. Exposure and nasal inflammation in workers heating polyurethane. Int Arch Occup Environ Health. 2002;75:468-74.

10. The Swedish Work Environment Authority. Occupational exposure limit values and measures against air contaminants. Stockholm (Sweden): Liber, 2005. AFS 2005:17.

11. Brown WE, Burkert AL. Biomarkers of diisocyanate exposure. Appl Occup Environ Hyg. 2002;17:840-5.

12. Sennbro CJ, Lindh $\mathrm{CH}$, Östin A, Welinder H, Jonsson BA, Tinnerberg H. A survey of airborne isocyanate exposure in 13 Swedish polyurethane industries. Ann Occup Hyg. 2004;48:405-14.

13. Sennbro CJ, Littorin M, Tinnerberg H, Jonsson BA. Upper reference limits for biomarkers of exposure to aromatic diisocyanates. Int Arch Occup Environ Health. 2005;78:541-6.

14. Health and Safety Executive. Organic isocyanates in air, MDHS 25/3. Sudbury (UK): Health and Safety Laboratory; 1999.

15. Sennbro CJ, Ekman J, Lindh CH, Welinder H, Jonsson BA, 
Tinnerberg H. Determination of isocyanates in air using 1(2-methoxyphenyl)piperazine-impregnated filters: long-term sampling performance and field comparison with impingers with dibutylamine. Ann Occup Hyg. 2004;48:415-24.

16. Östin A, Sundgren M, Ekman J, Lindahl R, Levin JO. Analysis of isocyanates with LC-MS/MS: isocyanates: sampling, analysis and health effects. West Conshohocken (PA): American Society for Testing and Materials; 2005.

17. Sennbro CJ, Lindh CH, Tinnerberg H, Welinder H, Littorin M, Jönsson BAG. Biological monitoring of exposure to toluene diisocyanate. Scand J Work Environ Health. 2004;30(5):371-8.

18. Sennbro CJ, Lindh CH, Tinnerberg H, Gustavsson C, Littorin $\mathrm{M}$, Welinder $\mathrm{H}$, et al. Development, validation and characterization of an analytical method for the quantification of hydrolysable urinary metabolites and plasma protein adducts of 2,4- and 2,6-toluene diisocyanate, 1,5-naphthalene diisocyanate and 4,4'-methylenediphenyl diisocyanate. Biomarkers. 2003;8:204-17.

19. Brock FH. Reactivity of aryl isocyanates. J Org Chem. 1959;24;1802-4.

20. Bernstein DI, Korbee L, Stauder T, Bernstein JA, Scinto J,
Herd ZL, et al. The low prevalence of occupational asthma and antibody-dependent sensitization to dipehylmethane diisocyanate in a plant engineered for minimal exposure to diisocyanates. J Allergy Clin Immunol. 1993;92:387-96.

21. Petsonk EL, Wang ML, Lewis DM, Siegel PD, Husberg BJ. Asthma-like symptoms in wood product plant workers exposed to methylene diphenyl diisocyanate. Chest. 2000;118:118393.

22. White WG, Morris MJ, Sugden E, Zapata E. Isocyanate-induced asthma in a car factory. Lancet. 1980;1(8171):756-60.

23. McDonald JC, Keynes HL, Meredith SK. Reported incidence of occupational asthma in the United Kingdom, 1989-97. Occup Environ Med. 2000;57:823-9.

24. Diller WF. Frequency and trends of occupational asthma due to toluene diisocyanate: a critical review. Appl Occup Environ Hyg. 2002;17:872-7.

25. Bello D, Herrick CA, Smith TJ, Woskie SR, Streicher RP, Cullen MR, et al. Skin exposure to isocyanates: reasons for concern. Environ Health Perspect. 2007;115:328-35.

Received for publication: 14 December 2006 